\title{
Integrated eicosanoid lipidomics and gene expression reveal decreased prostaglandin catabolism and increased 5-lipoxygenase expression in aggressive subtypes of endometrial cancer
}

DOI:

10.1002/path.5160

Document Version

Accepted author manuscript

Link to publication record in Manchester Research Explorer

\section{Citation for published version (APA):}

Cummings, M., Massey, K. A., Mappa, G., Wilkinson, N., Hutson, R., Munot, S., Saidi, S., Nugent, D., Broadhead, T., Wright, A. I., Barber, S., Nicolaou, A., \& Orsi, N. M. (2019). Integrated eicosanoid lipidomics and gene expression reveal decreased prostaglandin catabolism and increased 5-lipoxygenase expression in aggressive subtypes of endometrial cancer: Eicosanoid metabolism in endometrial cancer. The Journal of pathology, 247(1), 21-34. https://doi.org/10.1002/path.5160

\section{Published in:}

The Journal of pathology

\section{Citing this paper}

Please note that where the full-text provided on Manchester Research Explorer is the Author Accepted Manuscript or Proof version this may differ from the final Published version. If citing, it is advised that you check and use the publisher's definitive version.

\section{General rights}

Copyright and moral rights for the publications made accessible in the Research Explorer are retained by the authors and/or other copyright owners and it is a condition of accessing publications that users recognise and abide by the legal requirements associated with these rights.

\section{Takedown policy}

If you believe that this document breaches copyright please refer to the University of Manchester's Takedown Procedures [http://man.ac.uk/04Y6Bo] or contact uml.scholarlycommunications@manchester.ac.uk providing relevant details, so we can investigate your claim. 


\section{Integrated eicosanoid lipidomics and gene expression reveal decreased prostaglandin catabolism and increased 5-lipoxygenase expression in aggressive subtypes of endometrial}

cancer

Michele Cummings ${ }^{1}$, Karen A. Massey ${ }^{2}$, Georgia Mappa ${ }^{1}$, Nafisa Wilkinson ${ }^{3}$, Richard Hutson ${ }^{4}$, Sarika Munot ${ }^{4}$, Sam Saidi ${ }^{5}$, David Nugent ${ }^{4}$, Timothy Broadhead ${ }^{4}$, Alexander I. Wright ${ }^{1}$, Stuart Barber $^{6}$, Anna Nicolaou ${ }^{7} \&$ Nicolas M. Orsi ${ }^{1 *}$

${ }^{1}$ Leeds Institute of Cancer \& Pathology, Wellcome Trust Brenner Building, St James's University Hospital, Leeds, UK.

${ }^{2}$ Bradford School of Pharmacy, School of Life Sciences, University of Bradford, Bradford, UK

${ }^{3}$ Department of Cellular Pathology, University College London Hospital NHS Trust, London, $U K$.

4 Department of Gynaecological Oncology, St James's Institute of Oncology, St James's University Hospital, Leeds, UK.

${ }^{5}$ Central Clinical School, University of Sydney, Camperdown, New South Wales, Australia.

${ }^{6}$ Department of Statistics, University of Leeds, Leeds, UK.

This article has been accepted for publication and undergone full peer review but has not been through the copyediting, typesetting, pagination and proofreading process which may lead to differences between this version and the Version of Record. Please cite this article as doi: $10.1002 /$ path.5160 
${ }^{7}$ Laboratory for Lipidomics and Lipid Biology, Division of Pharmacy and Optometry, School of Health Sciences, Faculty of Biology, Medicine and Health, University of Manchester, Manchester Academic Health Science Centre, Manchester, UK.

*Correspondence to: NM Orsi, Leeds Institute of Cancer \& Pathology, Wellcome Trust Brenner Building, St James's University Hospital, Beckett Street, Leeds LS9 7TF, UK. Phone: +44 (0)1133438625.E-mail: n.m.orsi@leeds.ac.uk

Running title: Eicosanoid metabolism in endometrial cancer

Conflict of interest statement: All authors have no conflicts of interest.

Word count: 3999

Microarrays: Normalised gene expression data for the genes in this study are available in supplementary material (supplementary material, Table S1). 


\begin{abstract}
Eicosanoids comprise a diverse group of bioactive lipids which orchestrate inflammation, immunity and tissue homeostasis, and whose dysregulation has been implicated in carcinogenesis. Among the various eicosanoid metabolic pathways, studies of their role in endometrial cancer (EC) have very much been confined to the COX-2 pathway. This study aimed to determine changes in epithelial eicosanoid metabolic gene expression in endometrial carcinogenesis, to integrate these with eicosanoid profiles in matched clinical specimens and, finally, to investigate the prognostic value of candidate eicosanoid metabolic enzymes.
\end{abstract} Eicosanoids and related mediators were profiled using liquid chromatography-tandem mass spectrometry in fresh frozen normal, hyperplastic and cancerous (Types I and II) endometrial specimens $(n=192)$. Sample-matched epithelia were isolated by laser capture microdissection and whole genome expression analysis was performed using microarrays. Integration of eicosanoid and gene expression data showed that the accepted paradigm of increased COX-2 mediated prostaglandin production does not apply in EC carcinogenesis. Instead, there was evidence for decreased $\mathrm{PGE}_{2} / \mathrm{PGF}_{2 \alpha}$ inactivation via 15-hydroxyprostaglandin dehydrogenase (HPGD) in Type II ECs. Increased expression of 5-lipoxygenase (ALOX5) mRNA was also identified in Type II ECs, together with proportional increases in its product, 5-hydroxyeicosatetraenioic acid (5-HETE). Decreased HPGD and elevated ALOX5 mRNA expression were associated with adverse outcome, which was confirmed by immunohistochemical tissue microarray analysis of an independent series of EC specimens $(n=419)$. While neither COX-1 nor COX-2 protein 
expression had prognostic value, low HPGD combined with high ALOX5 expression associated with the worst overall and progression-free survival. These findings highlight HPGD and ALOX5 as potential therapeutic targets in aggressive EC subtypes.

Key words: lipidomics, eicosanoids, gene expression, endometrial cancer, cyclooxygenase, COX, LOX, 5-lipoxygenase, 15-PGDH, 15-hydroxyprostaglandin dehydrogenase, prognostic, endometrium 


\section{INTRODUCTION}

Endometrial cancer (EC) is the commonest gynaecological malignancy in the Western world and the fourth most common cancer affecting UK women. In 2015, there were almost 9,000 new diagnoses and over 2,000 deaths in the UK alone. The incidence of EC has risen by $57 \%$ in the UK since the early ' 90 s, partly due to changes in risk factors leading to unopposed oestrogen exposure, such as certain hormone replacement therapies and the increasing prevalence of obesity [1]. Traditionally, EC has been categorised into Types I and II according to aetiology, histopathology and clinical behaviour [2]. Type I (endometrioid EC, EEC), the commonest, hormone-sensitive form frequently develops from premalignant atypical hyperplasia [3], and often affects younger, perimenopausal women. By contrast, Type II ECs (non-endometrioid ECs) typically arise in postmenopausal atrophic endometrium and have poorer clinical outcomes. However, this dichotomy is overly simplistic, since grade 3 EECs and those with mixed endometrioid/non-endometrioid histology are now regarded clinically as Type II ECs due to their aggressive clinical behaviour [4]. Moreover, obesity/hormonal factors may also participate in the aetiology of Type II ECs [5]. Although low grade/low stage EC is frequently cured, survival of recurrent/advanced EC remains poor, highlighting the need for the development of novel targeted therapies [6].

Eicosanoids are polyunsaturated fatty acid (PUFA)-derived bioactive lipids which orchestrate physiological processes including immunity, inflammation and tissue repair. In this regard, 
chronic inflammation is a risk factor for many cancers as well as being critical for cancer progression [7]. Proinflammatory eicosanoids participate in the dialogue between transformed epithelial cells and surrounding stroma, thereby facilitating immunosuppression, proliferation, angiogenesis, invasion and metastasis through autocrine/paracrine mechanisms [8]. The most extensively studied eicosanoid metabolic pathway in cancer is the $\mathrm{COX}-2 / \mathrm{PGE}_{2}$ axis, where upregulation of the inducible COX isoform (COX-2; PTGS2) and concomitant increased $\mathrm{PGE}_{2}$ production are associated with malignant transformation [9]. High tumour PTGS2 expression is associated with adverse prognosis in various cancers, although inconsistent findings emanate from the relatively small studies conducted in EC [10-17]. COX enzymes (PTGS1, PTGS2) oxygenate arachidonic acid (AA) to $\mathrm{PGH}_{2}$, which is converted to $\mathrm{PGE}_{2}$ via $\mathrm{PGE}$ synthases. However, $\mathrm{PGH}_{2}$ is also converted to a range of prostanoids (other PGs, prostacyclin, thromboxanes) via specific synthases. In addition, COX-mediated metabolism generates Series-1 and -3 prostanoids (e.g. the anti-inflammatory $\mathrm{PGE}_{1}$ and $\mathrm{PGE}_{3}$ ) from dihomo- $\gamma$-linolenic acid (DGLA) and eicosapentaenoic acid (EPA), respectively. AA and other PUFAs are also oxygenated by lipoxygenase (LOX) and cytochrome P450 (CYP450) enzymes to form various bioactive lipids, including hydroxyeicosatetraenoic acids (HETE), hydroxyoctadecadienoic acids (HODE), leukotrienes, lipoxins and epoxyeicosatrienoic acids (EET) [18-22]. While many of these have been implicated in carcinogenesis in in vitro or murine models, studies on clinical specimens have largely relied on inference from expression of associated metabolic genes, or 
ELISA-based eicosanoid measurements, which often lack specificity [18]. Importantly, no attempts at profiling eicosanoids in clinical EC specimens have been made.

This study aimed to identify eicosanoid metabolic perturbations associated with malignant transformation/progression in EC by gene expression profiling of epithelia isolated from normal, hyperplastic and cancerous endometria, and integrating these with eicosanoid profiles obtained using sample-matched targeted mass spectrometry-based lipidomics analyses. It also investigated the prognostic significance of dysregulated eicosanoid metabolic enzymes by immunohistochemical analysis of a large independent series of archival EC specimens with longterm follow-up data. 


\section{MATERIALS AND METHODS}

\section{Patient recruitment}

Fresh endometrial tissue specimens $(n=192)$ were collected prospectively from 129 women (median age 66 years, range 31-89) undergoing hysterectomy for EC/atypical hyperplasia at St James's Hospital, Leeds between 2010 and 2013 (Cohort 1) (ethics approval 05/Q1107/41). Specimens used for lipidomics and gene expression analyses included normal $(n=53$; including proliferative $(n=13)$, secretory $(n=6)$, exogenous progestogen effect $(n=1)$ and atrophic (inactive/with weak proliferative activity; $n=33)$, atypical hyperplasia $(n=31)$ and cancerous ( $n=108 ; 55$ Type I (low/moderate grade EECs) and 53 Type II ECs (non-EECs, high grade EECs, mixed EEC/non-EEC histologies)). An independent retrospective cohort of 419 archival EC specimens (2005-2008) was used for immunohistochemical evaluation of potential prognostic biomarkers (Cohort 2). For both overall survival (OS) and progression-free survival (PFS), patients were censored at end of follow-up. OS was defined as time from diagnosis to death; PFS was defined as time from diagnosis to recurrence or death due to EC. Clinicopathological data from Cohorts 1 (cancer specimens) and 2 are given in Table 1.

Frozen tissue processing and laser capture microdissection

This article is protected by copyright. All rights reserved. 
Fresh specimens were frozen and cryosectioned [24]. Sections $(8 \mu \mathrm{m})$ were stained with haematoxylin and eosin and marked up to identify normal, hyperplastic and cancerous areas. Parallel sections were stained with alcohol-based cresyl violet and epithelial cells isolated for RNA extraction by laser capture microdissection. Glandular epithelium was harvested from normal endometria. Isolated epithelial cells were used to obviate the variable, confounding contribution of stromal cells on gene expression, and to focus on epithelial-specific markers amenable to prognostication on tissue microarrays (TMAs). Remaining frozen tissue was macrodissected on dry ice using pre-cooled instruments according to the marked-up slide for targeted lipidomics.

\section{RNA extraction and expression analysis}

RNA extraction was performed [24] using Ambion RNA-secure (ThermoFisher Scientific, Altrincham, UK) treatment $(1 / 20 \mathrm{v} / \mathrm{v})$ for stabilisation. RNA integrity was measured using RNA6000 nano chips on a Bioanalyzer (Agilent, Wokingham, UK) (median RIN 8.2, interquartile range 7.6-8.7). RNA samples ( $25 \mathrm{ng}$ ) were labelled with Cy3 using the Low Input Quick Amp Labeling kit (Agilent). Purified cRNA probes (600ng) were hybridised to Agilent SurePrint G3

human gene expression arrays (design ID 028004) as per the manufacturer's protocol and scanned using an Agilent $\mathrm{C}$ scanner. Data were extracted using Agilent Feature Extraction software (version 11.5.1.1). Arrays passed all Feature Extraction QC metrics. Expression data 
(supplementary material, Table S1) were normalised using Genespring GX 12.6 software (Agilent). Probes were annotated in Genespring according to Ensembl and Genbank assembly releases 77 and 205, respectively. Database resources (KEGG) [25] and published references were referred to for integration of eicosanoid metabolic pathway networks and for lipid mediator receptor expression.

\section{Targeted mediator lipidomics}

Lipid mediators were extracted and analysed by liquid chromatography-tandem mass spectrometry (LC-MS/MS) according to our published protocols [26]. In brief, tissue samples (25-75mg) were homogenised in ice-cold methanol/water using a Dounce homogeniser. Deuterated internal standards $\left(\mathrm{PGB}_{2}-d 4\right.$, 12-HETE- $d 8$; Cayman Chemicals, Cambridge Bioscience Ltd., Cambridge, UK) were added to all samples. Solutions were acidified to pH 3.0 and immediately applied to pre-conditioned C18-E solid phase extraction cartridges (Phenomenex, Macclesfield, UK) to reduce matrix effects. Chromatographic analysis of lipid extracts was performed on a C18 column (Luna, Phenomenex) using a Waters Alliance 2695 HPLC pump coupled to a triple quadrupole mass spectrometer with electrospray ionisation probe (Quattro Ultima; Waters, Elstree, UK). Chromatographic separation was performed using 
acetonitrile:methanol gradients. Prostanoids and hydroxy/epoxy PUFAs (supplementary material, Table S2) were detected using multiple reaction monitoring assays and quantified using calibration lines prepared with synthetic lipid standards (Cayman Chemicals). Results were expressed as pg/mg tissue protein (Bradford assay, Bio-Rad Laboratories, Hemel Hempstead, UK).

\section{Tissue microarrays and immunohistochemistry}

TMAs were constructed from formalin-fixed paraffin-embedded (FFPE) specimens using 3 x 0.6 $\mathrm{mm}$ cores/sample. Control TMAs included multiple normal human tissues. Antibodies to eicosanoid metabolic enzymes were selected after interrogation of lipid/gene expression profiles (Results; supplementary material, Table S3). Slide images were digitised at 20× magnification on Aperio XT slide scanners (Aperio Technologies, Vista, CA, USA). TMA cores were electronically de-arrayed and scored using software developed in-house [27, 28], that used colour deconvolution and pixel-level thresholding to separately quantify DAB (positive pixels) and haematoxylin (negative pixels) stains. Staining intensity was calculated as the positive pixel fraction (=positive pixels/(positive + negative pixels)). Core images were manually curated for the presence of sufficient viable tumour (inadequate cores were omitted from analysis). The score for each case was the mean fraction positive pixel scores across three cores.

\section{Statistics}


Statistical analysis was performed using $R$ [29] and IBM SPSS (Version 21, Armonk, NY, USA). All comparisons were performed using non-parametric methods (Kruskall-Wallis followed by Dunn's post hoc tests, or Mann-Whitney $U$ tests as appropriate). Lipid mediator-gene correlations used Spearman's Rho test. The Benjamini-Hochberg False Discovery Rate (FDR) Correction was applied for multiple comparisons. Kendall's correlation heat maps of lipid mediator data and hierarchical gene expression clustering (Ward's linkage algorithm) were generated in $R$. Survival analyses were performed using the Kaplan-Meier (log-rank test) method. Univariable and multivariable survival analyses were performed using Cox proportional hazards (CoxPH) models (assumption validity was tested using log-minus-log and Schoenfeld residual plots for categorical and continuous variables, respectively). TMA biomarker cut-off optimisation was performed using Cutoff Finder [30], via receiver-operator characteristic curve analysis (Manhattan distance). 


\section{RESULTS}

\section{Lipidomic analysis of eicosanoids and related mediators}

Lipid mediator profiles are given in Figure 1 (A-D). Species included COX-derived prostanoids (AA/DGLA/EPA derivatives) and their metabolites, and LOX-derived monohydroxy fatty acid derivatives of AA, DGLA and LA. A schematic outlining the main biochemical reactions determining the formation of AA-derived eicosanoids is shown in supplementary material, Figure S1. All normal endometrium (NE) subtypes were included in the analyses (Figure 1). Subgroup analysis of proliferative, secretory and atrophic NE specimens is provided in the supplementary material, Figure S2.

The predominant prostanoids were $\mathrm{AA}$ derivatives and, of these, $\mathrm{PGE}_{2}$ and $\mathrm{PGF}_{2 \alpha}$ were the most abundant. No significant differences in any primary prostanoid species across tissue types were observed (Figure 1A and B); neither were there any significant changes in the relative proportions of different AA-derived prostanoids (supplementary material, Figure S3). However, significant differences in levels of dihydro-15-keto derivatives of $\mathrm{PGE}_{2}$ and $\mathrm{PGF}_{2 \pm}$ were observed, where 13,14-dihydro-15-keto $\mathrm{PGE}_{2}$ was significantly reduced in both Type I and II ECs compared to NE (FDR $P<0.05$ and $<0.001$, respectively), and 13,14-dihydro-15-keto PGF $_{2 \alpha}$ was significantly reduced in Type II EC (FDR $P<0.05$ ) (Figure 1A). 13,14-dihydro-15-keto PGs are direct metabolites of 15-keto-PGs which in turn, are products of 15-hydroxyprostaglandin dehydrogenase (HPGD)-mediated prostaglandin catabolism [31]. Therefore, these findings 
suggest decreased rates of HPGD-mediated inactivation of $\mathrm{PGE}_{2}$ and $\mathrm{PGF}_{2 \alpha}$ in $\mathrm{EC}$, albeit without corresponding increases in their absolute levels.

12-HETE was the most abundant AA-derived LOX metabolite, in line with previous reports on NE [32], and was significantly lower in Type II compared to Type I EC (FDR $P<0.01$ ) (Figure 1C). There was a significant increase in the relative proportion of 5-HETE (as a fraction of total HETE) in Type II EC compared to NE (FDR $P<0.05$ ), while relative proportions of 11-, 12- and 15-HETE were unchanged (supplementary material, Figure S3).

Mono-hydroxylated derivatives of AA, LA, DGLA and other PUFAs can be formed from their precursor fatty acids via enzymatic and/or non-enzymatic catalysed reactions [18-21], (supplementary material, Figure S1). In light of this complexity, we investigated lipid mediator relationships within normal and neoplastic (hyperplastic and cancerous) endometrium (Figure 1 D-F). Across all categories, prostanoids correlated more strongly with each other than they did with hydroxy fatty acids and vice versa, and no inverse correlations between any species were evident. 12-HETE and 5-HETE correlated less well with other hydroxy fatty acids in all categories, whereas 11-HETE correlated better with prostanoids than did other hydroxy fatty acids.

\section{Pathway integration of eicosanoid mediators with epithelial gene expression}


Expression of genes connected with eicosanoid metabolism and transport as well as their known receptors was compared between normal, hyperplastic and cancerous endometrial epithelia (Supplementary Table S4). Hierarchical clustering of eicosanoid metabolic genes was also performed (supplementary material, Figure S4) together with hypothesis-driven metabolic/transporter gene:mediator correlations, focusing on AA metabolism since these pathways are the best described (supplementary material, Table S5). These analyses are summarised in an integrated pathway map (Figure 2). In general, the expression profile of eicosanoid metabolic enzyme/receptor genes in atypical hyperplasia most closely resembled that of Type I ECs with very few significant differences observed between these groups. The degree of up/downregulation was less pronounced in hyperplastic samples consistent with the fact that these represent a continuum in the development of invasive carcinoma. On the other hand, Type II EC gene expression profiles differed the most from those of the other groups (supplementary material, Table S4).

\section{Prostanoid synthetic and catabolic enzyme gene expression: evidence for decreased inactivation but not increased synthesis of $P G E_{2}$ and $P G F 2_{\alpha}$}

Increased COX isoform expression in neoplastic endometrium was not observed; rather, epithelial PTGS2 expression was downregulated in hyperplastic and Type II EC relative to NE, and PTGS1 was downregulated in neoplastic endometrium compared to NE, particularly in Type I EC (supplementary material, Table S4; Figure 2). However, a striking (14-fold) downregulation 
of $H P G D$ expression in Type II ECs compared to NE was observed, as well as decreased PG transporter (PGT/OATP2A1; SLCO2A1) expression in both EC types (supplementary material, Table S4; Figure 2). There were also significant changes in expression of various PG synthase mRNAs, with upregulation of certain PGE (PTGES2, PTGES3) and PGF synthases (AKR1B1, AKRIC1, CBR1), and downregulation of PGD (PTGDS, HPGDS), PGI prostacyclin (PTGIS) and TXB thromboxane (TXBAS1) synthases in either/both types of EC compared to NE (supplementary material, Table S4; Figure 2), although neither changes in absolute prostanoid levels (Figure 1) nor proportional shifts in prostanoid profiles (supplementary material, Figure S3) mirroring these changes were identified.

Sample-matched lipidomic and epithelial transcriptomic correlations were performed (supplementary material, Table S5; significant correlations summarised in Figure 2). $\mathrm{PGE}_{2}$, $\mathrm{PGF}_{2 \alpha}$ and $\mathrm{PGD}_{2}$ significantly correlated with both $P T G S 1$ and $P T G S 2$ expression, whereas $\mathrm{PGI}_{2}$ correlated only with PTGS1 and $\mathrm{TXB}_{2}$ with PTGS2. Although known to be produced nonenzymatically, the isoprostane 8-iso- $\mathrm{PGF}_{2 \alpha}$ correlated with PTGS1 expression in agreement with reports showing PTGS1-dependent production [33]. All prostanoids correlated with calciumdependent cytosolic phospholipase $\mathrm{A}_{2}(P L A 2 G 4 A)$ expression; $\mathrm{PGE}_{2}$ also correlated with calcium-independent cytosolic phospholipase PLA2G4C. Both these $\mathrm{PLA}_{2}$ genes were significantly downregulated in EC and PLA2G4C was also significantly downregulated in hyperplastic endometrium compared to NE (supplementary material, Table S4; Figure 2). 
PLA2G4A and PLA2G4C expression clustered with PTGS2 and PTGS1 expression, respectively (supplementary material, Figure S4), suggesting possible co-regulation, as shown for PTGS2 and PLA2G4A [34]. No correlations between prostanoids and their synthases were observed, suggesting possible redundancy or that the COX/PLA2G4A axis may be the principal determinant of PG synthesis. The $\mathrm{PGE}_{2}$ derivative 13,14-dihydro-15-keto-PGE 2 correlated with expression of the same genes as did its active precursor $\mathrm{PGE}_{2}$. Furthermore, this derivative correlated with $H P G D$ and the PG transporter $S L C O 2 A 1$ which also clustered most closely with HPGD. Similar relationships were identified with the $\mathrm{PGF}_{2 \alpha}$ derivative 13,14-dihydro-15-keto$\mathrm{PGF}_{2 \alpha}$ which correlated with both PLA2G4A and HPGD, and showed a trend towards correlating with $S L C O 2 A 1$ (FDR $P=0.076$ ) (supplementary material, Table S5). However, no relationship between PG levels and either HPGD or SLCO2Al expression was identified, perhaps due to the fact that parallel decreases in PTGS1/PTGS2 expression, and hence possibly PG production, are also observed in neoplastic endometrium.

Integrated pathway analysis of monohydroxy fatty acid and metabolic enzyme gene expression profiles

$L O X$ gene expression profiles revealed modest downregulation of $A L O X 12 B$ (epidermal type or 12R-LOX) and $A L O X 15 B$ (15-LOX-2) in Type II EC compared to NE, whereas no change in ALOX12 (platelet type or 12S-LOX) or ALOX15 (15-LOX-1) expression was identified. ALOX5 (5-LOX) expression was significantly increased in Type II ECs compared to NE, although 
downregulation of the accessory protein 5-LOX activating protein (FLAP/ALOX5AP) was also observed (Figure 2, supplementary material, Table S4). As with the prostanoids, all HETEs correlated with PLA2G4A expression. No correlations were observed between HETEs and relevant CYP450 genes (CYP1A1, CYP1A2, CYP1B1) [35], LOX or COX mRNAs (Figure 2, supplementary material, Table S5).

\section{Prognostic significance of eicosanoid metabolic enzyme genes in EC}

CoxPH survival analysis was performed on mRNA expression data based on the integrated lipidomics and gene expression analysis (supplementary material, Table S6). Of the $L O X$ genes, only $A L O X 5$ was prognostic: elevated $A L O X 5$ associated with worse PFS $(P=0.001)$, although mRNA expression of $A L O X 5 A P$ encoding its accessory protein, was not prognostic. Of the prostanoid metabolic enzyme mRNAs, elevated $H P G D$ was associated with better PFS $(P<0.05)$, elevated PTGS1 was associated with worse PFS $(P<0.05)$, whereas PTGS2, SLCO2A1, PLA2G4A and PLA2G4C were not prognostic. ALOX5, PTGS1 and HPGD were therefore selected for prognostic validation by immunohistochemistry (IHC) on TMAs (Cohort 2; Table 1). PTGS2 was also selected given its documented significance in carcinogenesis. All proteins localised to epithelial cells in both normal and cancer specimens (Figure 3), whereas stromal staining was weak/absent. The ALOX5 antibody also stained infiltrating leukocytes. The prognostic significance of ALOX5 and HPGD was independently confirmed, whereas PTGS1 and PTGS2 were not prognostic (supplementary material, Table S6). Applying optimised cutoffs, 
high ALOX5 protein expression significantly associated with worse OS and PFS, whereas high HPGD expression associated with better OS and PFS (Figure 4). Combining ALOX5 and HPGD expression scores further stratified patients into low-risk (ALOX5 low and HPGD high) intermediate (ALOX5 high or HPGD low) and high-risk groups (ALOX5 high and HPGD low). Thus, the combination of low HPGD and high ALOX5 defines a subset of patients with poor outcome (Figure 4), which was corroborated by analysis of an independent EC expression dataset (TCGA RNAseq; supplementary material, Figure S5), although this was not independently prognostic when adjusted for known prognostic variables in multivariable analysis (supplementary material, Table S7).

Association of eicosanoid metabolic enzyme expression with clinicopathological prognostic variables in EC

ALOX5 expression was positively associated with non-endometrioid histology, high grade, lymphovascular space invasion (LVSI), stage and nodal metastasis (FDR $P<0.05$; Table 2). HPGD expression was negatively associated with grade, LVSI, nodal positivity, myometrial invasion depth (FDR $P<0.05)$ and stage (FDR $P<0.001)$. PTGS1 associated positively only with non-endometrioid histology and LVSI (FDR $P<0.05)$. PTGS2 did not associate with any clinicopathological variable. 


\section{DISCUSSION}

In this study we identified changes in epithelial eicosanoid metabolic gene expression in EC malignant progression and integrated these with sample-matched tissue eicosanoid profiles which, to our knowledge, has not been attempted previously. This study offers novel insights into the regulation of PG metabolism in EC carcinogenesis and is the first to explore the prognostic significance of HPGD and LOX expression in EC.

The pro-carcinogenic role of $\mathrm{PGE}_{2}$ is well established [9]. Upregulation of the inducible COX isoform PTGS2 has been reported in many cancers, including EC [13, 36-39], although data on EC tissue $\mathrm{PGE}_{2}$ levels are lacking. The present study revealed that although PTGS2 mRNA positively correlated with $\mathrm{PGE}_{2}$ levels, neither PTGS2 expression nor $\mathrm{PGE}_{2}$ levels were increased in neoplastic endometrium. These different findings may be due to previous studies using few clinical samples and/or end-point RT-PCR to measure PTGS2 mRNA. Another factor could be the use of entire NE tissue as opposed to microdissected epithelia: Since immunohistochemical analysis showed that PTGS2 localises principally to the epithelium, previously observed increases in PTGS2 may reflect enrichment of epithelial cells in EC tissue compared to NE (where stroma predominates). Furthermore, we demonstrate that PTGS2 protein expression does not associate with any clinicopathological variable in EC, nor predict 
patient survival. Although PTGS2 expression is induced in response to pro-inflammatory stimuli, there is evidence for moderate constitutive PTGS2 expression in a variety of murine and human tissues [40, 41]. Conversely, constitutive COX isoform (PTGS1) overexpression has been implicated in some cancer types, most notably high grade serous ovarian carcinoma [42], although limited data exist for EC [36, 43, 44]. The present study showed PTGS1 downregulation in neoplastic endometrium, particularly Type I EC, although it positively correlated with $\mathrm{PGE}_{2}$ levels. Although PTGS1 protein expression associated with nonendometrioid EC subtypes and the presence of LVSI, no relationship with patient survival was identified.

$\mathrm{PGF}_{2 \pm}$ was another abundant prostanoid identified in this study. Pro-proliferative, pro-migratory and pro-angiogenic $\mathrm{PGF}_{2 \pm}$ actions on $\mathrm{EC}$ cell lines/tissue explants have been previously identified [45-47]. However, as for $\mathrm{PGE}_{2}$, our data showed that $\mathrm{PGF}_{2 \alpha}$ correlated with PTGS1/PTGS2 expression but did not differ in absolute levels between normal and neoplastic endometrium. Thus, it appears that levels of $\mathrm{PGE}_{2}$ and $\mathrm{PGF}_{2 \alpha}$ levels are maintained rather than increased in neoplastic endometrium. Taken together, these results do not support the notion that PTGS2 or PTGS1 upregulation and increased $\mathrm{PGE}_{2} / \mathrm{PGF}_{2 \alpha}$ synthesis are involved in endometrial carcinogenesis. Rather, the evidence presented herein points to decreased rates of $\mathrm{PGE}_{2} / \mathrm{PGF}_{2 \alpha}$ transport and inactivation, indicated by reduced levels of the PG importer SLCO2A1 and PG deactivating HPGD. In this regard, their inactive metabolites 13,14,-dihydro-15-keto-PGE 2 and 
13,14-dihydro-15-keto- $\mathrm{PGF}_{2 \alpha}$ were significantly reduced in cancerous endometrium (particularly Type II EC) and directly correlated with SLCO2Al and HPGD expression. Moreover, HPGD mRNA expression was strongly downregulated in Type II EC, and low HPGD mRNA and protein associated with adverse patient outcome. Subcellular compartmentalisation of $\mathrm{PGE}_{2}$ synthesis/release away from reuptake/oxidation has been proposed as a mechanism leading to fine control of localised autocrine/paracrine effects [48]. Thus, deregulation of $\mathrm{PGE}_{2} / \mathrm{PGF}_{2 \pm}$ reuptake/oxidation observed in EC, particularly Type II, may lead to localised increases in PGs in the tumour microenvironment, enhancing autocrine/paracrine signalling. HPGD is thought to act as a tumour suppressor by antagonising $\mathrm{PGE}_{2}$ production [49], and is known to be downregulated in several cancers [50], although data from EC were previously lacking. HPGD may also have tumour suppressive functions beyond its ability to modulate local $\mathrm{PGE}_{2}$ levels.

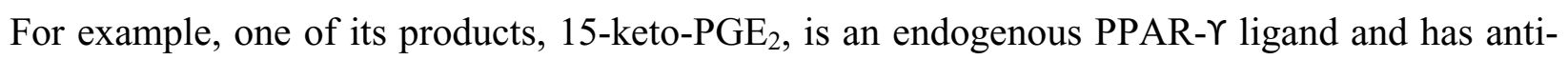
inflammatory and tumour suppressive properties [51-54]. However, in this study, 15-keto-PGE 2 was at the limit of detection, suggesting its rapid metabolism to 13,14 -dihydro-15-keto- $\mathrm{PGE}_{2}$, likely due to high levels of endometrial tissue PG reductase (PTGR1/PTGR2) activity. HPGD downregulation in normal colorectal mucosa confers resistance to chemopreventative effects of COX inhibitors [55]. Whether this effect operates in the chemotherapeutic setting is unknown, although gene-therapy and drug-based approaches to increase HPGD expression are possible strategies to circumvent this $[56,57]$. 
This study revealed epithelial ALOX5 mRNA expression to be increased in Type II EC. Moreover, of the $L O X$ genes, only $A L O X 5$ was prognostic, whereby increased epithelial $A L O X 5$ mRNA expression associated with adverse outcome, which was confirmed at the protein level by TMA immunohistochemistry in an independent EC cohort. As with the prostanoids, the ALOX5 product 5-HETE (and all identified HETE species) correlated with epithelial expression of cytosolic phospholipase $\mathrm{A}_{2}(P L A 2 G 4 A)$, a key enzyme required for plasma membrane AA release and subsequent eicosanoid biosynthesis [58]. Since this transcript was significantly downregulated in Type II EC, it is possible that the proportional—but not absolute—increases in 5-HETE observed in type II EC reflect relative increases of 5-HETE synthesis in the context of reduced free AA availability. However, specific LOX/CYP450 gene expression-HETE correlations were not identified, possibly reflecting the fact that that HETEs can be generated from AA via multiple pathways $[18,21,35]$, post-transcriptional/allosteric regulation of LOX activity $[59,60]$ or contributions to HETE synthesis from other cell types e.g. infiltrating leukocytes [20]. ALOX5 has previously been implicated in carcinogenesis, and proinflammatory, pro-carcinogenic actions have been attributed to ALOX5 metabolites (5-HETE, LTB4, 5-oxo-ETE) [20-22]. Unlike colorectal cancer, where ALOX5 upregulation appears early in the adenoma-carcinoma sequence [61], the data herein support significantly increased ALOX5 mRNA expression in Type II (high grade) ECs only. This study also showed that ALOX5 protein expression associated with high grade ECs and other adverse prognostic features including nodal metastasis. Indeed, while tumour ALOX5 expression promotes proliferation and survival [61- 
64], additional roles in stimulating angiogenesis [65], maintaining stemness [66] and promoting metastasis via immune effector cell interactions have also been reported [22, 67, 68]. In this study, ECs with high ALOX5 protein expression in combination with low HPGD associated with poorer prognosis than tumours with either feature alone. Thus, high ALOX5 and low HPGD define a subset of tumours with aggressive characteristics. Whether this indicates cooperation/synergy between the two enzymes is unclear, since ALOX5 products (5-HETE and LTB4) are not HPGD substrates, unlike 15-HETE [31]. Nevertheless, the superior effect of combined PTGS2/ALOX5 knockdown on cancer cell proliferation and VEGF secretion in vitro [69] and the anticarcinogenic effect of dual COX/ALOX5 inhibitors in a variety of preclinical cancer models [70-74] suggest cooperation between $\mathrm{PGE}_{2}$ and ALOX5 products in carcinogenesis/cancer progression. Strategies targeting ALOX5 in combination with COX/HPGD may therefore have therapeutic value in the treatment of aggressive EC subtypes, possibly in combination with conventional chemotherapy, where they could potentiate the effects of cytotoxic drugs, as has recently been shown for the dual COX/ALOX5 inhibitor licofelone in preclinical mouse models of ovarian cancer [75]. These approaches could be tested in mouse genetic models of Type II EC [76] or in patient-derived tumour xenograft models.

In summary, to the best of our knowledge, this is the largest study profiling eicosanoids in clinical cancer specimens and the only one to correlate these with eicosanoid metabolic gene expression. Our findings provide compelling evidence that the accepted paradigm of enhanced 
PTGS2 expression/PGE 2 production in malignant progression does not apply to EC. Instead, decreased $\mathrm{PGE}_{2} / \mathrm{PGF}_{2 \alpha}$ catabolism due to reduced $\mathrm{PG}$ import and/or inactivation via SLCO2A1/HPGD may increase local levels of these mediators. This study also found HPGD downregulation and ALOX5 upregulation to associate with adverse prognosis, particularly in combination, highlighting these enzymes as potential novel therapeutic targets in EC.

\section{ACKNOWLEDGEMENTS}

The authors are greatly indebted to Wellbeing of Women (grant number RG1210), Yorkshire Cancer Research (grant number LPP053) and the Pathological Society of Great Britain and Ireland (Career Development Fellowship awarded to NMO; grant number 1090) for funding, and to NHS staff and patients for their participation in the study. NMO is a National Institute for Health Research-funded Clinical Lecturer.

\section{AUTHOR CONTRIBUTIONS STATEMENT}

NMO, MC, AN, NW, SB and RH conceived, designed and supervised the study. MC, KM and GM performed experiments. SB, MC and AW performed data analyses and NW provided histopathological assessment. NW, RH, SM, DN, SS and TB facilitated collection of patient data 
and clinical specimens. MC and NMO drafted the manuscript. All authors provided comments on the manuscript and had final approval of the submitted version.

\section{ABBREVIATIONS}

AA: arachidonic acid

ALOX5: 5-lipoxygenase

ALOX5AP: 5-lipoxygenase activating protein (FLAP)

ALOX12: 12(S)-lipoxygenase (platelet type)

ALOX12B: 12(R)-lipoxygenase (epidermal type)

ALOX15: 15-lipoxygenase-1

ALOX15B: 15-lipoxygenase-2

CoxPH: Cox proportional hazards

CYP450: cytochrome P450

DGLA: dihomo- $\Upsilon$-linolenic acid

EEC: endometrioid endometrial cancer 
EET epoxyeicosatrienoic acid

EPA: eicosapentaenoic acid

HETE: hydroxyeicosatetraenoic acid

HETrE: hydroxyeicosatrienoic acid

HODE: hydroxyoctadecadienoic acid

HPGD: 15-hydroxyprostaglandin dehydrogenase

LA: linoleic acid

LC-MS/MS: liquid chromatography-tandem mass spectrometry

LOX: lipoxygenase

$\mathrm{LTB}_{4}$ : leukotriene $\mathrm{B}_{4}$

LVSI: lymphovascular space invasion

$\mathrm{LXA}_{4}$ : lipoxin $\mathrm{A}_{4}$

5-oxo-ETE: 5-oxo-eicosatetraenoic acid

$\mathrm{PGI}_{2}$ : prostacyclin

PLA2G4A/C: phospholipase A2 group IV A/C 
PUFA: polyunsaturated fatty acid

PTGR1/2: prostaglandin reductase-1/-2

PTGS1/2: prostaglandin G synthase-1/-2, COX-1/-2

SLCO2A1: solute organic anion carrier 2A1, prostaglandin transporter (PGT)

$\mathrm{TXB}_{2}$ : thromboxane $\mathrm{B}_{2}$ 


\section{REFERENCES}

1. Cancer Research UK cancer statistics; URL: http://www.cancerresearchuk.org/healthprofessional/cancer-statistics/statistics-by-cancer-type/uterine-cancer. (Accessed January 2018).

2. Bokhman JV. Two pathogenetic types of endometrial carcinoma. Gynecol Oncol 1983; 15: $10-17$.

3. Sanderson PA, Critchley HO, Williams AR, et al. New concepts for an old problem: the diagnosis of endometrial hyperplasia. Hum Reprod Update 2017; 23: 232-254.

4. Colombo N, Creutzberg C, Amant F, et al. ESMO-ESGO-ESTRO Endometrial Consensus Conference Working Group. ESMO-ESGO-ESTRO consensus conference on endometrial cancer: Diagnosis, treatment and follow-up. Radiother Oncol 2015; 117: 559-581.

5. Suarez AA, Felix AS, Cohn DE. Bokhman Redux: Endometrial cancer "types" in the 21st century. Gynecol Oncol 2017; 144: 243-249.

6. Rodriguez-Freixinos V, Karakasis K, Oza AM. New Targeted Agents in Endometrial Cancer: Are We Really Making Progress? Curr Oncol Rep 2016; 18: 23. 
7. Coussens LM, Werb Z. Inflammation and cancer. Nature 2002; 420: 860-867.

8. Wang D, Dubois RN. Eicosanoids and cancer. Nat Rev Cancer 2010; 10: 181-193.

9. Nakanishi M, Rosenberg DW. Multifaceted roles of PGE2 in inflammation and cancer. Semin Immunopathol 2013; 35: 123-137.

10. Jeon YT, Kang S, Kang DH, et al. Cyclooxygenase-2 and p53 expressions in endometrial cancer. Cancer Epidemiol Biomarkers Prev 2004; 13: 1538-4152.

11. Ferrandina G, Ranelletti FO, Gallotta V, et al. Expression of cyclooxygenase-2 (COX-2), receptors for estrogen (ER), and progesterone (PR), p53, ki67, and neu protein in endometrial cancer. Gynecol Oncol 2005; 98: 383-389.

12. Fowler JM, Ramirez N, Cohn DE, et al. Correlation of cyclooxygenase-2 (COX-2) and aromatase expression in human endometrial cancer: tissue microarray analysis. Am J Obstet Gynecol 2005; 192: 1262-1271. 
13. Hasegawa K, Ohashi Y, Ishikawa $\mathrm{K}$, et al. Expression of cyclooxygenase-2 in uterine endometrial cancer and anti-tumor effects of a selective COX-2 inhibitor. Int J Oncol 2005; 26: $1419-1428$.

14. Lambropoulou M, Alexiadis $\mathrm{G}$, Limberis $\mathrm{V}$, et al. Clinicopathologic and prognostic significance of cyclooxygenase-2 expression in endometrial carcinoma. Histol Histopathol 2005; 20: $753-759$.

15. Ohno Y, Ohno S, Suzuki N et al. Role of cyclooxygenase-2 in immunomodulation and prognosis of endometrial carcinoma. Int J Cancer 2005; 114: 696-701.

16. Jongen VH, Briët JM, de Jong RA, et al. Aromatase, cyclooxygenase 2, HER-2/neu, and p53 as prognostic factors in endometrioid endometrial cancer. Int J Gynecol Cancer 2009; 19: 670676.

17. Faloppa CC, Baiocchi G, Cunha IW, et al. $\mathrm{NF}^{\circ}{ }^{\mathrm{B}}$ and $\mathrm{COX}-2$ expression in nonmalignant endometrial lesions and cancer. Am J Clin Pathol 2014; 141: 196-203.

18. Astarita G, Kendall AC, Dennis EA, et al. Targeted lipidomic strategies for oxygenated metabolites of polyunsaturated fatty acids. Biochim Biophys Acta 2015; 1851: 456-468. 
19. Chen C, Wang DW. Cytochrome P450-CYP2 Family-epoxygenase role in inflammation and cancer. Adv Pharmacol 2015; 74: 193-221.

20. Kuhn H, Banthiya S, van Leyen K. Mammalian lipoxygenases and their biological relevance. Biochim Biophys Acta 2015; 1851: 308-330.

21. Powell WS, Rokach J. Biosynthesis, biological effects, and receptors of hydroxyeicosatetraenoic acids (HETEs) and oxoeicosatetraenoic acids (oxo-ETEs) derived from arachidonic acid. Biochim Biophys Acta 2015; 1851: 340-355.

22. Moore GY, Pidgeon GP. Cross-talk between cancer cells and the tumour microenvironment: the role of the 5-lipoxygenase pathway. Int J Mol Sci 2017; 18 pii: E236.

23. Creasman W. Revised FIGO staging for carcinoma of the endometrium. Int J Gynaecol Obstet 2009; 105: 109.

24. Cummings $\mathrm{M}$, McGinley $\mathrm{CV}$, Wilkinson $\mathrm{N}$, et al. A robust RNA integrity-preserving staining protocol for laser capture microdissection of endometrial cancer tissue. Anal Biochem 2011; 416: 123-125. 
25. Kanehisa M, Goto S, Sato Y, et al. Data, information, knowledge and principle: back to metabolism in KEGG. Nucleic Acids Res 2014; 42 (Database issue): D199-205.

26. Massey KA, Nicolaou A. Lipidomics of oxidized polyunsaturated fatty acids. Free Radic Biol Med 2013; 59: 45-55.

27. TMAi URL: http://www.virtualpathology.leeds.ac.uk/research/analysis/

28. Wu Y, Grabsch H, Ivanova $\mathrm{T}$, et al. Comprehensive genomic meta-analysis identifies intratumoural stroma as a predictor of survival in patients with gastric cancer. Gut 2013; 62: 11001111.

29. R Core Team (2017). R: A language and environment for statistical computing. R Foundation for Statistical Computing, Vienna, Austria. URL http://www.R-project.org/.

30. Budczies J, Klauschen F, Sinn BV, et al. Cutoff Finder: a comprehensive and straightforward Web application enabling rapid biomarker cutoff optimization. PLoS One 2012; 7: e51862. 
31. Tai H-H, Ensor CM, Tong M, et al. Prostaglandin catabolizing enzymes. Prostaglandins Other Lipid Mediat 2002; 68-69: 483-493.

32. Ihno Y, Ishihara O, Kinoshita K. Synthesis of 12-hydroxyeicosatetraenoic acid by human endometrium and decidua. Prostaglandins Leukot Essent Fatty Acids 1993; 49: 609-613.

33. Favreau F, Petit-Paris I, Hauet T, et al. Cyclooxygenase 1-dependent production of F2isoprostane and changes in redox status during warm renal ischemia-reperfusion. Free Radic Biol Med 2004; 36: 1034-1042.

34. Matsui $\mathrm{M}$, Chu $\mathrm{Y}$, Zhang $\mathrm{H}$, et al. Promoter RNA links transcriptional regulation of inflammatory pathway genes. Nucleic Acids Res 2013; 41: 10086-10109.

35. Choudhary D, Jansson I, Stoilov I, et al. Metabolism of retinoids and arachidonic acid by human and mouse cytochrome P450 1b1. Drug Metab Dispos 2004; 32: 840-847.

36. Tong BJ, Tan J, Tajeda L, et al. Heightened expression of cyclooxygenase-2 and peroxisome proliferator-activated receptor-delta in human endometrial adenocarcinoma. Neoplasia 2000; 2: 483-490. 
37. Jabbour HN, Milne SA, Williams AR, et al. Expression of COX-2 and PGE synthase and synthesis of PGE(2) in endometrial adenocarcinoma: a possible autocrine/paracrine regulation of neoplastic cell function via EP2/EP4 receptors. Br J Cancer 2001; 85: 1023-1031.

38. Fujiwaki R, Iida K, Kanasaki H, et al. Cyclooxygenase-2 expression in endometrial cancer: correlation with microvessel count and expression of vascular endothelial growth factor and thymidine phosphorylase. Hum Pathol 2002; 33: 213-219.

39. Knapp P, Chabowski A, Błachnio-Zabielska A. Expression of estrogen receptors $\left( \pm,^{2}\right)$, cyclooxygenase- 2 and aromatase in normal endometrium and endometrioid cancer of uterus. $A d v$ Med Sci 2013; 58: 96-103.

40. Kirkby N, Chan MV, Zaiss AK, et al. Systematic study of constitutive cyclooxygenase-2 expression: Role of $\mathrm{NF}^{\circ}{ }^{\circ} \mathrm{B}$ and NFAT transcriptional pathways. Proc Natl Acad Sci U S A 2016; 113: $434-439$.

41. Zidar N, Odar K, Glavac D, et al. Cyclooxygenase in normal human tissues - is COX-1 really a constitutive isoform, and COX-2 an inducible isoform? Cell Mol Med 2009; 13: 3753-3763. 
42. Wilson AJ, Fadare O, Beeghly-Fadiel A, et al. Aberrant over-expression of COX-1 intersects multiple pro-tumorigenic pathways in high-grade serous ovarian cancer. Oncotarget 2015; 6: $21353-21368$.

43. Uotila PJ, Erkkola RU, Klemi PJ. The expression of cyclooxygenase-1 and -2 in proliferative endometrium and endometrial adenocarcinoma. Ann Med 2002; 34: 428-433.

44. Sugimoto T, Koizumi T, Sudo T et al. Correlative expression of cyclooxygenase-1 (Cox-1) and human epidermal growth factor receptor type-2 (Her-2) in endometrial cancer. Kobe J Med Sci 2007; 53: 177-187.

45. Sales KJ, Milne SA, Williams AR, et al. Expression, localization, and signaling of prostaglandin F2 alpha receptor in human endometrial adenocarcinoma: regulation of proliferation by activation of the epidermal growth factor receptor and mitogen-activated protein kinase signaling pathways. J Clin Endocrinol Metab 2004; 89: 986-993.

46. Sales KJ, List T, Boddy SC, et al. A novel angiogenic role for prostaglandin F2alpha-FP receptor interaction in human endometrial adenocarcinomas. Cancer Res 2005; 65: 7707-7716. 
47. Sales KJ, Boddy SC, Jabbour HN. F-prostanoid receptor alters adhesion, morphology and migration of endometrial adenocarcinoma cells. Oncogene 2008; 27: 2466-2477.

48. Nomura T, Chang HY, Lu R, et al. Prostaglandin signaling in the renal collecting duct: release, reuptake, and oxidation in the same cell. J Biol Chem 2005; 280: 28424-28429.

49. Myung SJ, Rerko RM, Yan M, et al. 15-Hydroxyprostaglandin dehydrogenase is an in vivo suppressor of colon tumorigenesis. Proc Natl Acad Sci U S A 2006; 103: 12098-12102.

50. Tai H-H. Prostaglandin catabolic enzymes as tumor suppressors. Cancer Metastasis Rev 2011; 30: 409-417.

51. Lu D, Han C, Wu T. 15-PGDH inhibits hepatocellular carcinoma growth through 15-ketoPGE2/PPAR ${ }^{3}$-mediated activation of p21WAF1/Cip1. Oncogene 2014; 33: 1101-1112.

52. Chang EY, Chang YC, Shun CT, et al. Inhibition of prostaglandin reductase 2, a putative oncogene overexpressed in human pancreatic adenocarcinoma, induces oxidative stress-mediated cell death involving xCT and CTH gene expressions through 15-Keto-PGE2. PLoS One 2016; 11: e0147390. 
53. Chou WL, Chuang LM, Chou CC, et al. Identification of a novel prostaglandin reductase reveals the involvement of prostaglandin E2 catabolism in regulation of peroxisome proliferatoractivated receptor gamma activation. J Biol Chem 2007; 282: 18162-18172.

54. Yao L, Chen W, Song K, et al. 15-hydroxyprostaglandin dehydrogenase (15-PGDH) prevents lipopolysaccharide (LPS)-induced acute liver injury. PLoS One 2017; 12: e0176106.

55. Yan M, Myung SJ, Fink SP, et al. 15-Hydroxyprostaglandin dehydrogenase inactivation as a mechanism of resistance to celecoxib chemoprevention of colon tumors. Proc Natl Acad Sci U S A 2009; 106: 9409-9413.

56. Na HK, Park JM, Lee HG, et al. 15-Hydroxyprostaglandin dehydrogenase as a novel molecular target for cancer chemoprevention and therapy. Biochem Pharmacol 2011; 82: 1352 1360.

57. Choi SH, Kim BG, Robinson J, et al. Synthetic triterpenoid induces 15-PGDH expression and suppresses inflammation-driven colon carcinogenesis. J Clin Invest 2014; 124: 2472-2482.

58. Scott KF, Sajinovic M, Hein J, et al. Emerging roles for phospholipase A2 enzymes in cancer. Biochimie 2010; 92: 601-610. 
59. Wecksler AT, Kenyon V, Deschamps JD, et al. Substrate specificity changes for human reticulocyte and epithelial 15-lipoxygenases reveal allosteric product regulation. Biochemistry 2008; 47: 7364-7375.

60. Rådmark O, Samuelsson B. Regulation of the activity of 5-lipoxygenase, a key enzyme in leukotriene biosynthesis. Biochem Biophys Res Commun 2010; 396: 105-110.

61. Melstrom LG, Bentrem DJ, Salabat MR, et al. Overexpression of 5-lipoxygenase in colon polyps and cancer and the effect of 5-LOX inhibitors in vitro and in a murine model. Clin Cancer Res 2008; 14: 6525-6530.

62. Avis I, Hong SH, Martinez A, et al. Five-lipoxygenase inhibitors can mediate apoptosis in human breast cancer cell lines through complex eicosanoid interactions. FASEB $J$ 2001; 15: 2007-2009.

63. Sarveswaran S, Thamilselvan V, Brodie $\mathrm{C}$, et al. Inhibition of 5-lipoxygenase triggers apoptosis in prostate cancer cells via down-regulation of protein kinase C-epsilon. Biochim Biophys Acta 2011; 1813: 2108-2117. 
64. Sarveswaran S, Chakraborty D, Chitale D, et al. Inhibition of 5-lipoxygenase selectively triggers disruption of c-Myc signaling in prostate cancer cells. J Biol Chem 2015; 290: $4994-$ 5006.

65. Chatterjee M, Das S, Roy K, et al. Overexpression of 5-lipoxygenase and its relation with cell proliferation and angiogenesis in 7,12-dimethylbenz $( \pm)$ anthracene-induced rat mammary carcinogenesis. Mol Carcinog 2013; 52: 359-369.

66. Saraveswaran S, Varma N, Morisetty S, et al. Inhibition of 5-lipoxygenase downregulates stemness and kills prostate cancer stem cells by triggering apoptosis via activation of c-Jun Nterminal kinase. Oncotarget 2016; doi: 10.18632/oncotarget.13422.

67. Wejksza K, Lee-Chang C, Bodogai M, et al. Cancer-produced metabolites of 5-lipoxygenase induce tumor-evoked regulatory B cells via peroxisome proliferator-activated receptor \pm . $J$ Immunol 2013; 190: 2575-8254.

68. Wen Z, Liu H, Li M, et al. Increased metabolites of 5-lipoxygenase from hypoxic ovarian cancer cells promote tumor-associated macrophage infiltration. Oncogene 2015; 34: 1241-1252. 
69. Park SW, Heo DS, Sung MW. The shunting of arachidonic acid metabolism to 5lipoxygenase and cytochrome p450 epoxygenase antagonizes the anti-cancer effect of cyclooxygenase-2 inhibition in head and neck cancer cells. Cell Oncol (Dordr) 2012; 35: 1-8.

70. Mohammed A, Janakiram NB, Li Q, et al. Chemoprevention of colon and small intestinal tumorigenesis in APC(Min/+) mice by licofelone, a novel dual 5-LOX/COX inhibitor: potential implications for human colon cancer prevention. Cancer Prev Res (Phila) 2011; 4: 2015-2026.

71. Sharma S, Lee J, Zhou J, et al. Chemopreventive efficacy and mechanism of licofelone in a mouse lung tumor model via aspiration. Cancer Prev Res (Phila) 2011; 4: 1233-1242.

72. Shi HY, Lv FJ, Zhu ST, et al. Dual inhibition of 5-LOX and COX-2 suppresses esophageal squamous cell carcinoma. Cancer Lett 2011; 309: 19-26.

73. Madka V, Mohammed A, Li Q, et al. Chemoprevention of urothelial cell carcinoma growth and invasion by the dual COX-LOX inhibitor licofelone in UPII-SV40T transgenic mice. Cancer Prev Res (Phila) 2014; 7: 708-716.

74. Mohammed A, Janakiram NB, Madka V, et al. Targeting pancreatitis blocks tumor-initiating stem cells and pancreatic cancer progression. Oncotarget 2015; 6: 15524-15539. 
75. Hirst J, Pathak HB, Hyter S, et al. Licofelone enhances the efficacy of paclitaxel in ovarian cancer by reversing drug resistance and tumor stem-like properties. Cancer Res 2018; 78: 43704385.

76. Wild PJ, Ikenberg K, Fuchs TJ, et al. p53 suppresses type II endometrial carcinomas in mice and governs endometrial tumour aggressiveness in humans. EMBO Mol Med 2012; 4: 808-24.

*77. Smith SK, Abel MH, Kelly RW et al. The synthesis of prostaglandins from persistent proliferative endometrium. J Clin Endocrinol Metab 1982; 55: 284-289.

*78. Rees MC, Anderson AB, Demers LM, et al. Endometrial and myometrial prostaglandin release during the menstrual cycle in relation to menstrual blood loss. J Clin Endocrinol Metab 1984; 58: 813-818.

*79. Swanson ML, Lei ZM, Swanson PH et al. The expression of thromboxane A2 synthase and thromboxane A2 receptor gene in human uterus. Biol Reprod 1992; 47: 105-117. 
*80. Tapia A, Vilos C, Marín JC, et al. Bioinformatic detection of E47, E2F1 and SREBP1 transcription factors as potential regulators of genes associated to acquisition of endometrial receptivity. Reprod Biol Endocrinol 2011; 9: 14.

*81. Anaya, J. OncoLnc: linking TCGA survival data to mRNAs, miRNAs, and lncRNAs. PeerJ Comput Sci 2016; 2: e67.

* Cited only in supplementary materials. 


\section{TABLES}

\section{Table 1.}

\begin{tabular}{|c|c|c|}
\hline & Cohort 1 (FF); $n=108$ & Cohort 2 (FFPE); $n=419$ \\
\hline Median follow-up (months) & 50.1 & 79.7 \\
\hline Age (years); median (range) & $67(39-89)+$ & $67(28-95)$ \\
\hline Histopathological subtype & $N(\%)$ & $N(\%)$ \\
\hline Endometrioid (grades 1\&2) & $55(50.9)$ & $243(58.0)$ \\
\hline Endometrioid (grade 3) & $10(9.2)$ & $54(12.9)$ \\
\hline Serous & $19(17.6)$ & $35(8.4)$ \\
\hline Clear cell & $5(4.6)$ & $11(2.6)$ \\
\hline Mixed & $4(3.7)$ & $49(11.6)$ \\
\hline Carcinosarcoma & $15(13.9)$ & $25(6.0)$ \\
\hline Undifferentiated & $0(0)$ & $1(0.2)$ \\
\hline Mucinous & $0(0)$ & $1(0.2)$ \\
\hline Surgical stage (FIGO 2009) & $N(\%)$ & $\boldsymbol{N}(\%)^{*}$ \\
\hline 1 & $79(73.1)$ & $262(62.5)$ \\
\hline$\|$ & $7(6.5)$ & $42(10.0)$ \\
\hline III & $14(13.0)$ & $84(20.0)$ \\
\hline IV & $8(7.4)$ & $31(7.4)$ \\
\hline Grade (FIGO) & $N(\%)$ & $N(\%)$ \\
\hline 1 & $37(34.3)$ & $147(35.1)$ \\
\hline 2 & $20(18.5)$ & $104(24.8)$ \\
\hline 3 & $51(47.2)$ & $168(40.1)$ \\
\hline LVSI & $N(\%)$ & $N(\%)$ \\
\hline Yes & $50(46.3)$ & $214(51.1)$ \\
\hline No & $58(53.7)$ & $205(48.9)$ \\
\hline Lymph node status & $N(\%)$ & $N(\%)$ \\
\hline Positive & $11(10.2)$ & $63(15.0)$ \\
\hline Negative & $60(55.6)$ & $269(64.2)$ \\
\hline No lymphadenectomy & $37(34.3)$ & $87(20.8)$ \\
\hline
\end{tabular}

Table 1. Patient demographic data for prospective and retrospective EC samples.

This article is protected by copyright. All rights reserved. 
Details of prospectively collected fresh frozen endometrial cancer cases (Cohort 1; lipidomics and gene expression analysis) as well as the independent retrospective cohort used for prognostic marker validation by IHC (Cohort 2). * Staging data for Cohort 2 were converted from the FIGO 1988 to the FIGO 2009 staging system [23] according to individual patients' pathology reports.

t The age range in the table for Cohort 1 corresponds to the cancer cases only. A breakdown of age ranges (in years; median (range)) for the different sample types in Cohort 1 is as follows: Normal endometrium: 60 (31-86); atypical hyperplasia: 66 (45-89); Type I endometrial cancer: 62 (39-89); Type II endometrial cancer: 71 (49-87). Abbreviations: FF: fresh frozen, FFPE: formalin fixed paraffin embedded, FIGO: International Federation of Gynaecological Oncologists, LVSI: lymphovascular space invasion. 
Table 2

\begin{tabular}{|c|c|c|c|c|c|c|c|c|}
\hline Variable & HPGD, Median (IQR) & $P$ & PTGS1, Median (IQR) & $P$ & PTGS2, Median (IQR) & $P$ & ALOX5, Median (IQR) & $P$ \\
\hline $\begin{array}{l}\text { Histology } \\
\text { EEC } \\
\text { Non-EEC/mixed histology }\end{array}$ & $\begin{array}{l}0.08(0.03-0.23) \\
0.06(0.04-0.13)\end{array}$ & 0.334 & $\begin{array}{l}0.013(0.005-0.042) \\
0.025(0.006-0.074)\end{array}$ & 0.029 & $\begin{array}{l}0.75(0.64-0.83) \\
0.74(0.65-0.81)\end{array}$ & 0.834 & $\begin{array}{l}0.59(0.43-0.78) \\
0.67(0.49-0.85)\end{array}$ & 0.037 \\
\hline $\begin{array}{l}\text { Grade (FIGO) } \\
1 \text { or } 2 \\
3\end{array}$ & $\begin{array}{l}0.09(0.03-0.26) \\
0.06(0.03-0.13)\end{array}$ & 0.027 & $\begin{array}{l}0.013(0.005-0.041) \\
0.018(0.005-0.070)\end{array}$ & 0.353 & $\begin{array}{l}0.74(0.63-0.82) \\
0.75(0.67-0.83)\end{array}$ & 0.336 & $\begin{array}{l}0.58(0.42-0.77) \\
0.66(0.50-0.84)\end{array}$ & 0.018 \\
\hline $\begin{array}{l}\text { Stage (FIGO 2009) } \\
\text { I or II } \\
\text { III or IV }\end{array}$ & $\begin{array}{l}0.09(0.04-0.24) \\
0.05(0.03-0.09)\end{array}$ & $<0.001$ & $\begin{array}{l}0.014(0.005-0.052) \\
0.016(0.004-0.052)\end{array}$ & 0.773 & $\begin{array}{l}0.74(0.64-0.83) \\
0.74(0.66-0.82)\end{array}$ & 0.773 & $\begin{array}{l}0.59(0.43-0.77) \\
0.68(0.48-0.85)\end{array}$ & 0.037 \\
\hline $\begin{array}{l}\text { LVSI } \\
\text { Absent } \\
\text { Present }\end{array}$ & $\begin{array}{l}0.10(0.04-0.23) \\
0.06(0.03-0.15)\end{array}$ & 0.018 & $\begin{array}{l}0.013(0.004-0.047) \\
0.021(0.006-0.070)\end{array}$ & 0.028 & $\begin{array}{l}0.74(0.64-0.82) \\
0.75(0.65-0.84)\end{array}$ & 0.637 & $\begin{array}{l}0.59(0.42-0.76) \\
0.62(0.47-0.84)\end{array}$ & 0.048 \\
\hline $\begin{array}{l}\text { Lymph node status } \\
\text { Negative } \\
\text { Positive }\end{array}$ & $\begin{array}{l}0.07(0.03-0.22) \\
0.05(0.03-0.09)\end{array}$ & 0.028 & $\begin{array}{l}0.014(0.005-0.051) \\
0.023(0.006-0.055)\end{array}$ & 0.751 & $\begin{array}{l}0.75(0.66-0.83) \\
0.75(0.67-0.82)\end{array}$ & 0.773 & $\begin{array}{l}0.59(0.44-0.79) \\
0.77(0.51-0.87)\end{array}$ & 0.027 \\
\hline $\begin{array}{l}\text { Depth myometrial invasion } \\
\text { Inner half } \\
\text { Outer half }\end{array}$ & $\begin{array}{l}0.09(0.04-0.22) \\
0.06(0.03-0.15)\end{array}$ & 0.027 & $\begin{array}{l}0.015(0.005-0.054) \\
0.015(0.004-0.051)\end{array}$ & 0.568 & $\begin{array}{l}0.75(0.66-0.83) \\
0.74(0.64-0.82)\end{array}$ & 0.655 & $\begin{array}{l}0.61(0.45-0.77) \\
0.61(0.44-0.82)\end{array}$ & 0.627 \\
\hline $\begin{array}{l}\text { Cervical stromal invasion } \\
\text { Absent } \\
\text { Present }\end{array}$ & $\begin{array}{l}0.07(0.03-0.19) \\
0.06(0.03-0.14)\end{array}$ & 0.334 & $\begin{array}{l}0.015(0.005-0.049) \\
0.016(0.006-0.055)\end{array}$ & 0.655 & $\begin{array}{l}0.74(0.64-0.82) \\
0.76(0.65-0.82)\end{array}$ & 0.655 & $\begin{array}{l}0.60(0.44-0.79) \\
0.62(0.45-0.80)\end{array}$ & 0.655 \\
\hline
\end{tabular}

Table 2. Association of tumour protein biomarker expression with clinicopathological variables in EC.

Patients (Cohort 2) were grouped according to known tumour-associated prognostic clinicopathological variables. The table shows median plus interquartile range (IQR) of tumour protein expression (fraction positive pixels from IHC of TMAs) in each group. Groups were compared using Mann-Whitney $U$ tests and $P$ values corrected for multiple comparisons using FDR. Abbreviations: EEC: endometrioid endometrial cancer, FIGO: International Federation of Gynaecology and Obstetrics, LVSI: lymphovascular space invasion. 


\section{FIGURE LEGENDS}

\section{Figure 1. Eicosanoid and related lipid mediators in normal, hyperplastic and cancerous}

endometrial tissue.

(A-C) Mediators were analysed by liquid chromatography-tandem mass spectroscopy (LC$\mathrm{MS} / \mathrm{MS}$ ); data reported as pg mediator/mg tissue protein. Individual sample values are plotted on a $\log$ scale (green: normal endometrium $(n=53)$, blue: hyperplastic endometrium (atypical hyperplasia; $n=31)$, red: Type I EC $(n=55)$, purple: Type II EC $(n=53)$. Median values for each group are indicated by black bars. A) Series-2 prostanoid species derived from arachidonic acid via COX-mediated reactions, as well as the dihydro-15-keto derivatives resulting from metabolic inactivation of $\mathrm{PGE}_{2}$ and $\mathrm{PGF}_{2 \alpha}$ by 15 -hydroxyprostaglandin dehydrogenase (HPGD); note: $\mathrm{PGI}_{2}$ and $\mathrm{TXA}_{2}$ are unstable and detected as 6-keto $\mathrm{PGF}_{1 \pm}$ and $\mathrm{TXB}_{2}$, respectively. B) Series-1 (DGLA-derived) and -3 (EPA-derived) prostanoid species (via COX) plus the non-enzymatically produced isoprostane 8-iso- $\mathrm{PGF}_{2 \alpha}$. C) monohydroxy fatty acids (produced via LOX/ nonenzymatic lipid peroxidation). Precursor fatty acids and their respective chemical notations are indicated below each mediator. Statistical significance (corrected using the False Discovery Rate) between groups is indicated by asterisks: *** $P<0.001, * * P<0.01, * P<0.05$. (D - F) Correlation heat maps of lipid mediator data (pg/mg tissue) were constructed for each tissue type. Heat maps obtained for normal endometrial samples are compared with those from (D) hyperplastic, (E) Type I EC and (F) Type II EC samples. Strength of correlation between each mediator (Kendall's Tau coefficient) is indicated by the colour key. Abbreviations: EC: 
endometrial cancer, $\mathrm{PGI}_{2}$ : prostacyclin, TX: thromboxane, dh15-keto: 13,14-dihydro-15-keto, HETE: hydroxyeicosatetraenoic acid, HODE: hydroxyoctadecadienoic acid, HETrE: hydroxyeicosatrienoic acid, AA: arachidonic acid, DGLA: dihomo- $\curlyvee$-linolenic acid,; EPA eicosapentaeonic acid, LA: linoleic acid.

\section{Figure 2. Integrated eicosanoid pathway analysis in endometrial carcinogenesis.}

The figure indicates the major pathways of eicosanoid biosynthesis from arachidonic acid, together with known catabolic (inactivation) pathways. Eicosanoids (arachidonic acid metabolites) detected in endometrial tissues (53 normal, 31 atypical hyperplasia, 55 Type I and 53 Type II endometrial cancers) via LC-MS/MS are indicted in grey circles. Sample-matched gene expression data were obtained by microarray analysis of RNA extracted from laser capture microdissected epithelia and Spearman's Rho correlations (supplementary material Table S5) performed to determine eicosanoid-gene expression relationships. Eicosanoid metabolic enzyme/transporter genes that positively correlated with each eicosanoid (False Discovery Rate corrected $P<0.05)$ are indicated in red within the appropriate grey circles. Eicosanoid metabolic enzyme and transporter genes showing differential epithelial expression across tissue types $(>1.5$ median fold change, FDR $P<0.05$; supplementary material, Table S4) are indicated next to the appropriate arrows on the pathway diagram. Similarly, differentially expressed eicosanoid receptor genes are indicated, together with their known ligands (eicosanoids/related mediators). Graphs depict median fold change compared to normal endometrium in both gene expression 
and eicosanoid levels (where there was a significant difference between tissue types): green bars: atypical hyperplasia, blue bars: Type I endometrial cancer, red bars: Type II endometrial cancer. Mediator abbreviations: DHET: dihydroxyeicosatrienoic acid, HETE: hydroxyeicosatetraenoic acid, HPETE: hydroxyperoxyeicosatetraenoic acid, HODE: hydroxyoctadecadienoic acid, 5-oxoETE: 5-oxo-eicosatetraenoic acid, $\mathrm{PGI}_{2}$ : prostacyclin, $\mathrm{TXB}_{2}$ : thromboxane $\mathrm{B}_{2}$. Gene abbreviations: ABCC4: ATP binding cassette subfamily $\mathrm{C}$ member 4, ALOX: lipoxygenase, ALOX5AP: 5-LOX activating protein (FLAP), AKR1: aldo-keto reductase family 1 (PGF synthesis), CBR1: carbonyl reductase-1 (PGF synthesis), CYP: cytochrome p450, EPHX2: soluble epoxide hydrolase, HPGD: 15-hydroxyprostaglandin dehydrogenase, HPGDS: haematopoietic PGD synthase, OXER1: oxoeicosanoid receptor-1, PLA2: phospholipase $\mathrm{A}_{2}$, PTGDS: PGD synthase, PTGER: PGE receptor, PTGES2/3 PGE synthase-2/-3, PTGFR: PGF receptor, PTGIR: prostacyclin receptor, PTGIS: prostacyclin synthase, PTGRI: PG reductase-1, PTGS1/2: cyclooxygenase-1/2, SLCO2A1: solute organic anion carrier 2A1 (PG transporter), $T X B A S$ : thromboxin A synthase.

\section{Figure 3. Immunohistochemical staining of endometrial cancer tissue microarrays.}

Right panel: example TMA cores of endometrial cancers stained with antibodies against selected eicosanoid metabolic enzymes, showing a range of staining intensities. Staining intensity scores (assessed electronically on digitised slides and expressed as fraction positive pixels) are indicated underneath each core. Left panel: cores of normal (atrophic) endometrium stained in parallel 
with the same antibodies. Abbreviations: ALOX5: 5-lipoxygenase, HPGD: 15hydroxyprostaglandin dehydrogenase, PTGS1: cyclooxygenase-1, PTGS2: cyclooxygenase-2.

Figure 4. Survival of endometrial cancer patients stratified according to immunohistochemical assessment of tumour HPGD and ALOX5 expression.

Kaplan-Meier progression-free (PFS) and overall survival (OS) curves plus log-rank $P$-values for patients $(n=419)$ stratified using optimised cutoffs (determined using Receiver-Operator Characteristic curves) for (A,B) HPGD, (C,D) ALOX5 and (E,F) combined HPGD and ALOX5 expression. High and low values are indicated by ' and ", respectively, and number of patients falling into each category is also indicated. Protein expression was determined electronically from digitised tissue microarray slides (fraction positive pixels). Cutoffs were fraction positive pixel values of e 0.283 and e 0.765 for HPGD and ALOX5, respectively. Abbreviations: HPGD: 15-hydroxyprostraglandin dehydrogenase,; ALOX5: 5-lipoxygenase.

SUPPLEMENTARY MATERIAL ONLINE

Supplementary materials and methods NO

Supplementary figure legends NO, because the legends are embedded in the figures

This article is protected by copyright. All rights reserved. 
Figure S1. Schematic representation of the main biochemical pathways involved in arachidonic acidderived eicosanoid biosynthesis and metabolism

Figure S2. Subgroup analysis of normal endometrial specimens

Figure S3. Proportions of arachidonic acid-derived eicosanoid species in endometrial tissues

Figure S4. Hierarchical clustering of eicosanoid metabolic enzyme and transporter gene expression in normal, hyperplastic and cancerous endometrial epithelia

Figure S5. Survival analysis of patients stratified according to HPGD and ALOX5 mRNA expression using the TCGA endometrial cancer dataset

Table S1. Expression of eicosanoid metabolic pathway and receptor genes in normal, hyperplastic and cancerous endometrial epithelia (log2 normalised median-centred values)

Table S2. Panel of lipid mediators included in the targeted lipidomics assay. Eicosanoids and related fatty acid-derived mediators (prostanoids, hydroxy and epoxy fatty acids) and their precursor fatty acids are indicated

Table S3. Antibodies used for immunohistochemistry on tissue microarrays

Table S4. Comparison of eicosanoid metabolic pathway enzyme, transporter and receptor gene expression in normal, hyperplastic and cancerous endometrial epithelia 
Table S5. Correlation of eicosanoid levels with sample-matched gene expression values.

Table S6. Association of eicosanoid metabolic enzyme/transporter gene expression with endometrial cancer survival

Table S7. Univariable and multivariable survival analysis of patients stratified according immunohistochemical assessment of tumour HPGD and ALOX5 expression 

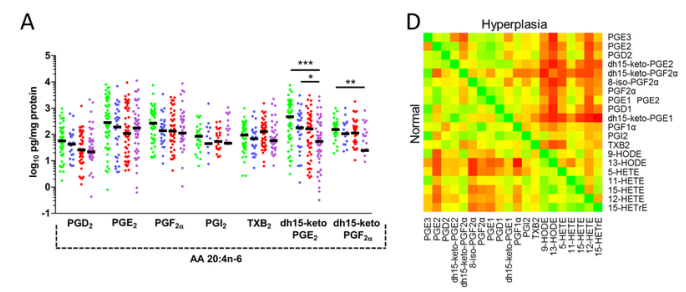

B

E

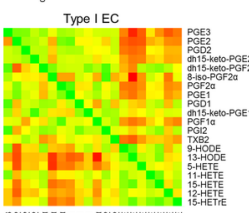

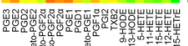

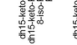

$\mathrm{F}$

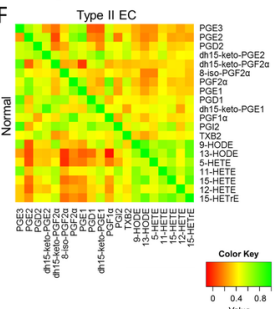

PATH_5160_FIG_1_redone RP.tif 


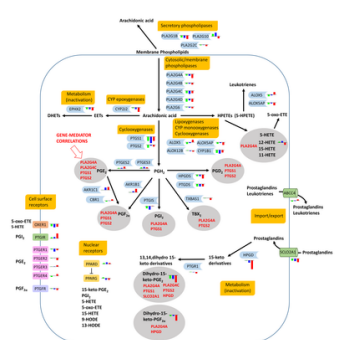

PATH_5160_FIG_2_redone RP.tif 


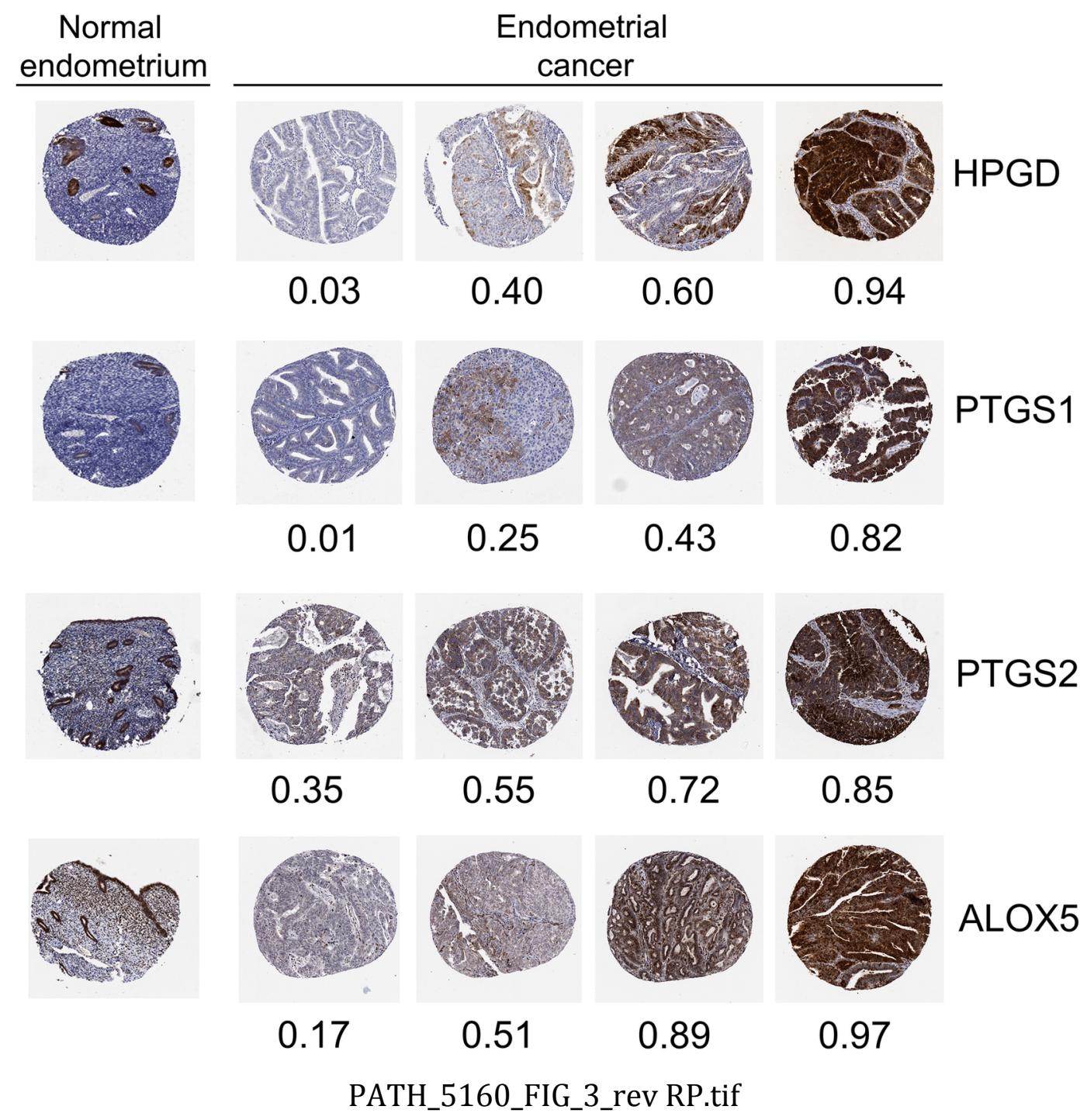

This article is protected by copyright. All rights reserved. 

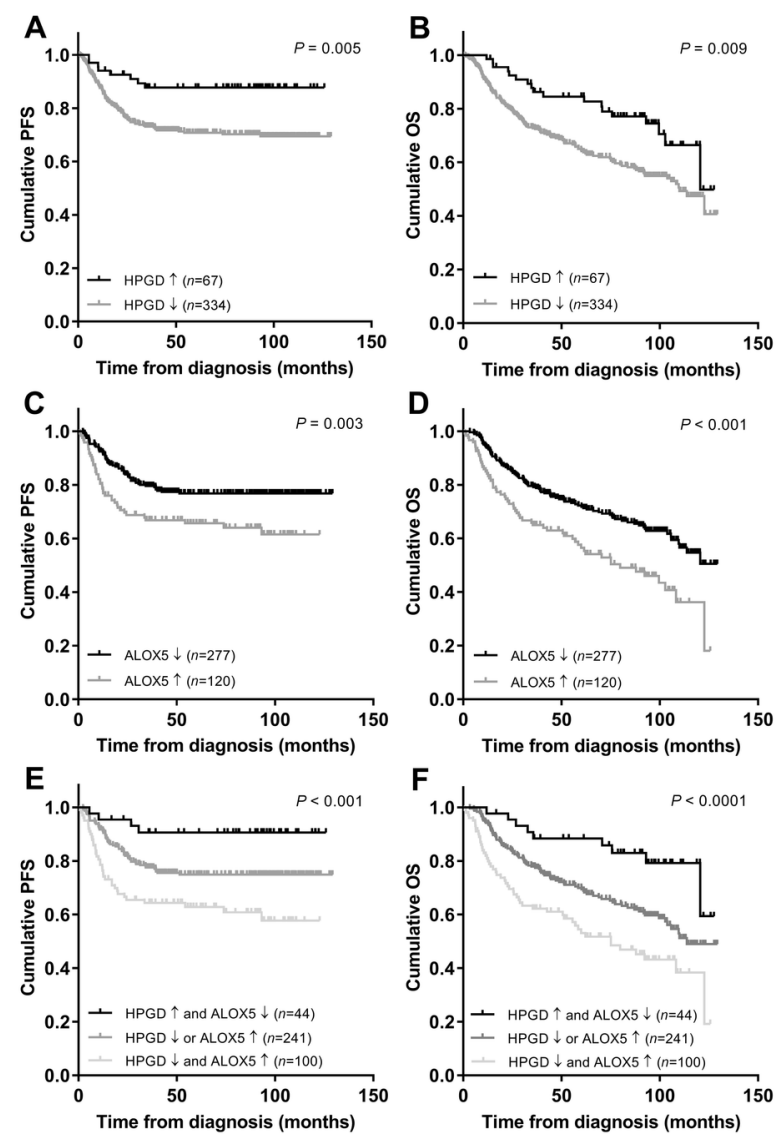

PATH_5160_FIG_4_rev RP.tif 